\title{
SUCCESSFUL PREGNANCY OUTCOME IN RECURRENT PHEOCHROMOCYTOMA: a clinical case report
}

\author{
Evelina Praneviciene ${ }^{1}$, Birute Zilaitiene ${ }^{2,3}$, Lina Radzeviciene $^{2,3}$, Lina Barsiene $^{3}$, Rasa Verkauskiene $^{2,3}$, Tomas Birzietis $^{4}$
}

${ }^{1}$ Faculty of Medicine, Medical Academy, Lithuanian University of Health Sciences; ${ }^{2}$ Institute of Endocrinology, Medical Academy, Lithuanian University of Health Sciences; ${ }^{3}$ Department of Endocrinology, Medical Academy, Lithuanian University of Health Sciences; ${ }^{4}$ Department of Obstetrics and Gynaecology, Medical Academy, Lithuanian University of Health Sciences.

\section{Introduction}

Pheochromocytoma in pregnancy is a very rare and potentially dangerous situation for mother and fetus.

Failure to diagnose this condition or suboptimal management can be disastrous for mother and/or fetus, because of raised catecholamine levels.

\section{Case}

- A 22-year-old pregnant woman (8 weeks' gestation) with hypertension and a suspected recurrence of pheochromocytoma was referred to the Endocrinology Department in March 2014. The pregnancy was unplanned.

- In physical examination her height $-176 \mathrm{~cm}$, weight $-74 \mathrm{~kg}$, blood pressure and pulse were $156 / 90 \mathrm{mmHg}$ and $92 \mathrm{beats} / \mathrm{min}$ respectively.

- Laboratory investigations: with normal Aldosterone / Renin ratio.

\begin{tabular}{|c|c|c|c|c|c|}
\hline & \multicolumn{4}{|c|}{ Results } & \multirow{2}{*}{ Reference range (unit) } \\
\hline Test Date & 20-MAR-2014 & 22-APR-2014 & 15-JUN-2014 & 12-AUG-2014 & $0.0 .456(\mathrm{nmol} / \mathrm{l})$ \\
\hline Metanephrin & 0.42 & 1.01 & 0.21 & 0.86 & $0-153$ \\
\hline Normetanephrin & $>16.38$ & $>16.38$ & 46.52 & 3.1 & $3.8-5.3(\mathrm{mmol} / \mathrm{l})$ \\
\hline Potasium & 3.4 & & & 15.6 & $1.6-14.7(\mathrm{ng} / \mathrm{l})$ \\
\hline Renin & 16.81 & & & 580 & $35-300(\mathrm{ng} / \mathrm{l})$ \\
\hline Aldosterone & 633 & & & 466.92 & $0-100(\mu \mathrm{g} / \mathrm{l})$ \\
\hline Chromogranin A & & 361.18 & 385.72 & $\mathrm{nmol} / \mathrm{l})$ \\
\hline
\end{tabular}

- From her medical history it was already known that she underwent right adrenalectomy due to pheochromocytoma in March 2012.

- Six months later increased blood preassure till 160/100 mmHg was observed. On abdominal CT scan (June 2013) - right adrenal gland removed, several $\sim 1.1 \times 1.0 \mathrm{~cm}$ lymph nodes are visible, left adrenal gland structural, without any additional masses in it. Metanephrin and normetanephrin tests indicated significantly elevated catecholamines levels. Unfortunately abdominal MRI (August 2013, September 2014) and MIBG scans (October 2013, February 2014) did not reveal possible source of catecholamines hyperproduction as well. Genetic testing results were negative.

- Hypertention during first trimester was treated with Labetalol $600 \mathrm{mg} / \mathrm{day}$, Metildopa $1000 \mathrm{mg} / \mathrm{day}$, potassium chloride 1500 $\mathrm{mg} /$ day. Phenoxybenzamine hydrochloride was added later on and titrated till $100 \mathrm{mg} / \mathrm{day}$ in order to reach satisfactory blood pressure control.

- In September, 2014 the patient had uncomplicated delivery of a healthy boy (weight - $2890 \mathrm{~g}$, height - $47 \mathrm{~cm}$, Apgar score 9-9) via Caesarean section (spinal anesthesia). She is breast-feeding and continues Labetalol 900 mg/day for hypertension control.

Further investigations are planned to identify localization of pheochromocytoma.

\section{Conclusions}

This case illustrates that adequate medical management in the case of pheochromocytoma predispose the successful pregnancy outcome.

\section{References:}

Biggar MA, Lennard TW. Systematic review of phaeochromocytoma in pregnancy.Br J Surg. 2013 Jan;100(2):18290. doi: 10.1002/bjs.8976. Epub 2012 Nov 23. Review. 